\title{
Enantioselective Total Synthesis of Fluvirucinin $B_{1}$
}

\author{
Guillaume Guignard, ${ }^{\dagger}$ Núria Llor, ${ }^{\dagger}$ Elies Molins, ${ }^{\dagger}$ Joan Bosch, ${ }^{*}{ }^{\dagger}$ and Mercedes Amat ${ }^{*} \dagger$ \\ ${ }^{\dagger}$ Laboratory of Organic Chemistry, Faculty of Pharmacy, and Institute of Biomedicine (IBUB), University of Barcelona, \\ 08028-Barcelona, Spain \\ *Institut de Ciència de Materials (CSIC), Campus UAB, 08193-Cerdanyola, Spain
}

Supporting Information Placeholder

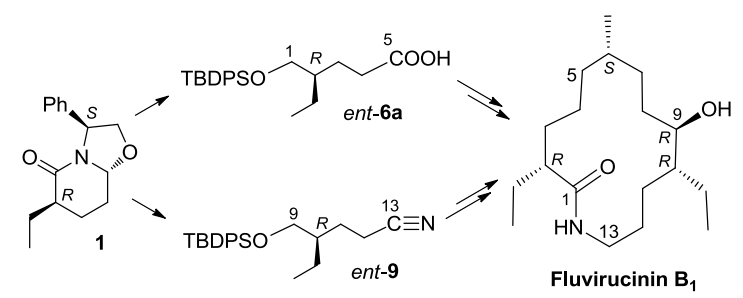

ABSTRACT: A convergent synthesis of fluvirucinin $\mathrm{B}_{1}$ from acid ent-6a and nitrile ent-9, involving an organocopper coupling, a stereoselective allylation, a ring-closing metathesis reaction, and a stereoselective hydrogenation as the key steps, is reported. The starting building blocks have been prepared in a straightforward manner from a common phenylglycinol-derived lactam 1. An unprecedented regioselective oxidation of phenylglycinol-derived secondary amines $\mathbf{5}$ to carboxylic acids $\mathbf{6}$ has been developed.

Fluvirucins are 14-membered macrocyclic lactams isolat$\mathrm{ed}^{1-3}$ from the fermentation broth of actinomycete strains. They are glycosides characterized by the presence of an aminosugar moiety (L-mycosamine, its 4-epimer, or an $\mathrm{N}$ substituted derivative) attached at the C-3 or C-9 positions of the core lactam nucleus through a hydroxy group. They also incorporate a methyl or ethyl substituent at the C-2 (1Shydroxyethyl in fluvirucin $\mathrm{A}_{2}$ ), C-6 (absent in some members), and $\mathrm{C}-10$ positions (Figure 1). Fluvirucins possess important and varied biological activities, such as antifungal, ${ }^{1}$ antibiotic, ${ }^{2}$ antiviral, ${ }^{2}$ and anthelmintic. ${ }^{3}$ In particular, fluvirucin $B_{1}$ (Sch 38516) exhibits potent antifungal ${ }^{1 \mathrm{a}, \mathrm{c}}$ and anti-influenza virus $^{2 a}$ activities, ${ }^{4}$ the latter partially retained in the corresponding aglycon fluvirucinin $\mathrm{B}_{1}{ }^{2 \mathrm{~b}}$

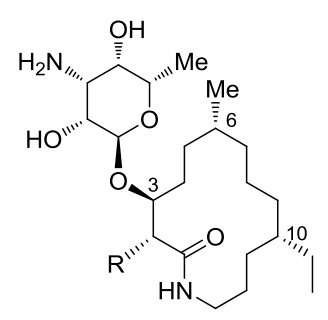

Fluvirucin $A_{1}(R=M e)$

Fluvirucin $A_{2}\left[R=(S)-C H(O H) C H_{3}\right.$ Fluvirucin $B_{0}$ Fluvirucin $\mathrm{B}_{\mathbf{0}} \quad(\mathrm{R}=\mathrm{H})$ ] Fluvirucin $B_{1}(S c h 38516) \quad(R=M e)$ Fluvirucin $\mathbf{B}_{\mathbf{2}}$ (Sch 38518) $\left[\mathrm{R}=\mathrm{Et}\left(4^{\prime}-e p i\right)\right]$ Fluvirucin $B_{3}(S c h 39185) \quad(R=E t)$

Figure 1. Representative fluvirucins.

Although only one total synthesis of a fluvirucin has been reported, ${ }^{5}$ the synthesis of the macrolactam aglycons of fluvirucins, known as fluvirucinins, has received more attention. ${ }^{6-10}$ A key point in the synthesis of fluvirucinins is the stereocon- trolled assembly of the stereocenters on the macrocyclic ring. Taking into account that all fluvirucinins B possess the same substitution and stereochemical patterns at the C-2 (R-Et), C-9 $(S-\mathrm{OH})$, and $\mathrm{C}-10(R-\mathrm{Et})$ positions, differing only in the $\mathrm{C}-6$ substituent (none in fluvirucinin $\mathrm{B}_{0}, S$-Me in $\mathrm{B}_{1}, S$-Et in

\section{Scheme 1. Unified Synthetic Strategy to Fluvirucinins B}
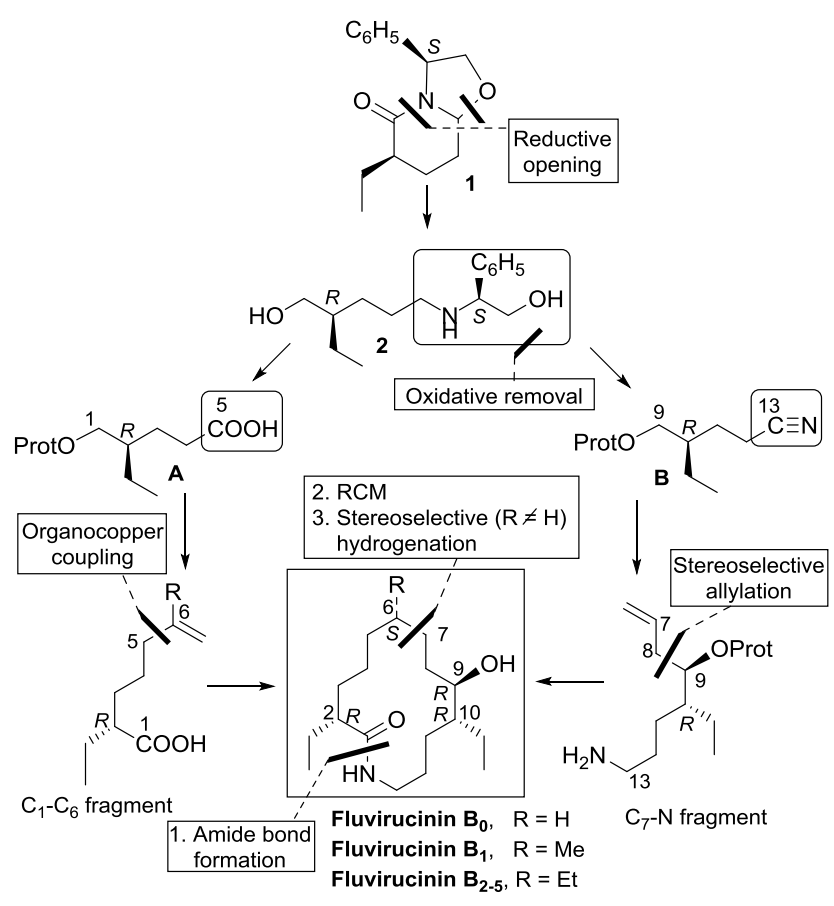
$B_{2-5}$ ), we envisaged a unified synthetic strategy to these macrolactams in which the C-2 and C-10 ethyl substituents would come from a common enantiopure amino diol $\mathbf{2}$, easily accessible by reductive opening of oxazolopiperidone lactam $\mathbf{1}^{11}$ Scheme 1 outlines our synthetic plan.

Amino diol 2 would be converted to a 5-hydroxypentanoic acid derivative $\mathbf{A}$ by oxidative removal of the phenylglycinol moiety and then to the $\mathrm{C}_{1}-\mathrm{C}_{6}$ fragment of fluvirucinins $\mathrm{B}$ by copper-catalyzed coupling of the corresponding iodide with an appropriately substituted ( $\mathrm{R}=\mathrm{H}, \mathrm{Me}$ or Et) alkenyl Grignard reagent. In turn, the secondary amino group of amino diol 2 would be oxidized to a cyano group, and the resulting 5hydroxypentanenitrile $B$ would be converted to the $\mathrm{C}_{7}-\mathrm{N}$ fragment of fluvirucinins $\mathrm{B}$ after the incorporation of the C-9 stereogenic center by a stereoselective allylation of an aldehyde. Linkage of the two fragments by an amidation reaction, followed by a ring-closing metathesis and stereoselective hydrogenation of the resultant alkene would complete the synthesis of the target fluvirucinins B. The success of our synthetic plan would rely on the development of efficient procedures for the oxidative removal of the phenylglycinol moiety present in amino diol $\mathbf{2}$ to afford 5-hydroxypentanoic acid and 5-hydroxypentanenitrile derivatives.

The conversion of a secondary amine to a carboxylic acid is a challenging, unprecedented transformation. Taking into account that primary amines are oxidized to nitro derivatives by treatment with $m$-chloroperbenzoic acid, ${ }^{12}$ we decided to study this oxidation using a set of phenylglycinol-derived secondary amines structurally related to 2 .

To our delight, treatment of the $O$-protected amino diols $\mathbf{5 a}-$ d with an excess of $m$-CPBA (4.2 equiv) in refluxing $\mathrm{CH}_{2} \mathrm{Cl}_{2}$ directly afforded the corresponding carboxylic acids $\mathbf{6 a}-\mathbf{d}$, bearing a variety of substituents (ethyl, benzyl, isopropylidenedioxy) in good yields (Scheme 2). Considering that amino diols $\mathbf{4}$ are available with virtually any type of substitution pattern, ${ }^{11}$ the above oxidative procedure opens a general synthetic entry to enantiopure 5-hydroxypentanoic acid derivatives.

The formation of carboxylic acids 6 can be accounted for by considering the generation of the nonconjugated nitrones $7^{13}$ and their $m$-CPBA-promoted oxidative cleavage ${ }^{14}$ with subsequent oxidation of the resulting aldehyde. The oxidative cleavage also produces a nitroso derivative, which was isolated as the corresponding nitroso dimer $\mathbf{8}$ (Scheme 3 ).

Scheme 2. Oxidative Removal of the Chiral Inductor. Access to Enantiopure $O$-Protected 5-Hydroxypentanoic Acids

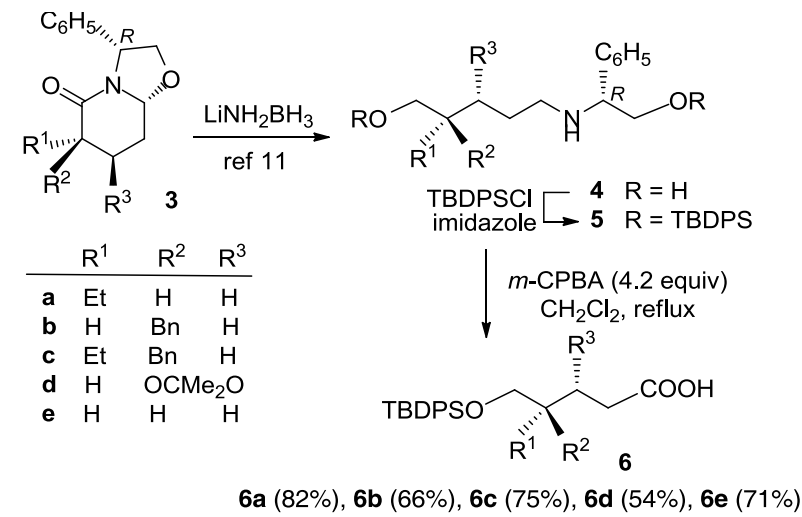

In support of this mechanism, nitrone 7e, prepared by $\mathrm{Na}_{2} \mathrm{WO}_{4} /$ hydrogen peroxide-urea oxidation ${ }^{13 \mathrm{~b}}$ of the simple secondary amine $\mathbf{5 e}$, was converted to hydroxypentanoic acid derivative $6 \mathbf{6}$ ( $45 \%$ from $5 \mathbf{e})$ and dimer 8 by treatment with $m$ CPBA (2.5 equiv).

Scheme 3. Proposed Mechanism for the $m$-CPBA-Promoted Oxidation of Secondary Amines 5

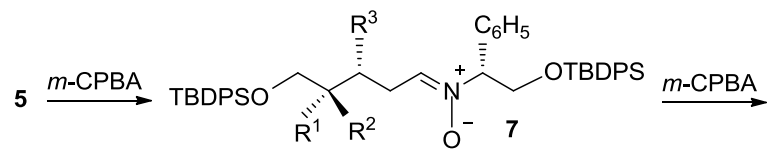

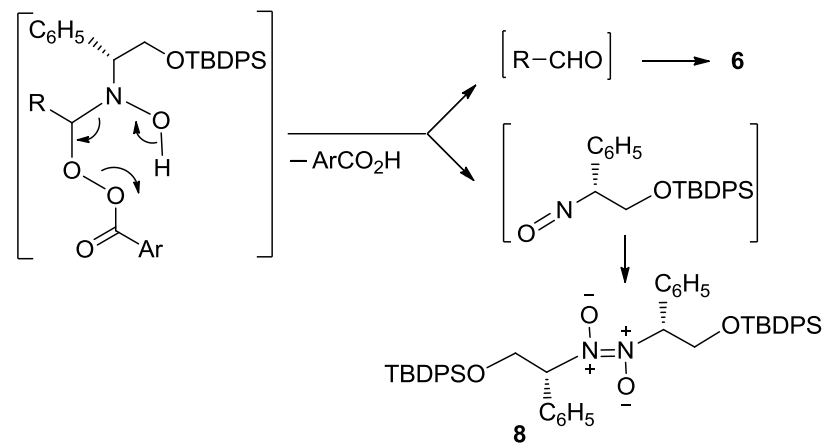

On the other hand, the generation of a 5-hydroxypentanenitrile by oxidative cleavage of the phenylglycinol moiety of the starting $O$-protected amino diol was successfully accomplished in a single step using molecular iodine in aqueous ammonia. ${ }^{15}$ In this way, secondary amine $\mathbf{5 a}$ was converted to nitrile 9 in $71 \%$ yield (Scheme 4).

This transformation involves the initial generation of an imine and its reaction with ammonia to form an aminal, which decomposes to a primary amine and an imine. Subsequent oxidation and hydrolytic steps lead to the nitrile and (tertbutyldiphenylsilyloxy)methyl phenyl ketone, regardless of the regioselectivity of the initial oxidation.

\section{Scheme 4. Oxidation of Secondary Amine 5a to Nitrile 9}

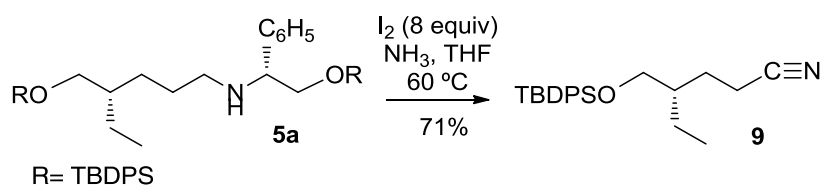

Having developed straightforward procedures for the conversion of secondary amines $\mathbf{5}$ to functionalized carboxylic acids 6 and nitrile 9, to evaluate the feasibility of the unified strategy outlined in Scheme 1, we undertook the synthesis of fluvirucinin $\mathrm{B}_{1}$. To achieve the required $2 R$ and $10 R$ configuration characteristic of fluvirucinins $B$, we started from the $(S)$-phenylglycinol-derived secondary amine ent-4a $(=2)$, which was converted, as in the above $(R)$-phenylglycinol series, to hydroxy acid ent-6a (A; Prot = TBDPS) and hydroxy nitrile ent $\mathbf{- 9}(\mathbf{B} ;$ Prot $=$ TBDPS $)$.

Scheme 5 outlines the synthesis of fluvirucinin $B_{1}$. The $C_{1}-$ $\mathrm{C}_{6}$ fragment (compound 12) was prepared from carboxylic acid ent-6a, which was converted, via an alcohol, to iodide $\mathbf{1 0}$. 
Scheme 5. Total Synthesis of Fluvirucinin $\mathrm{B}_{1}{ }^{a}$

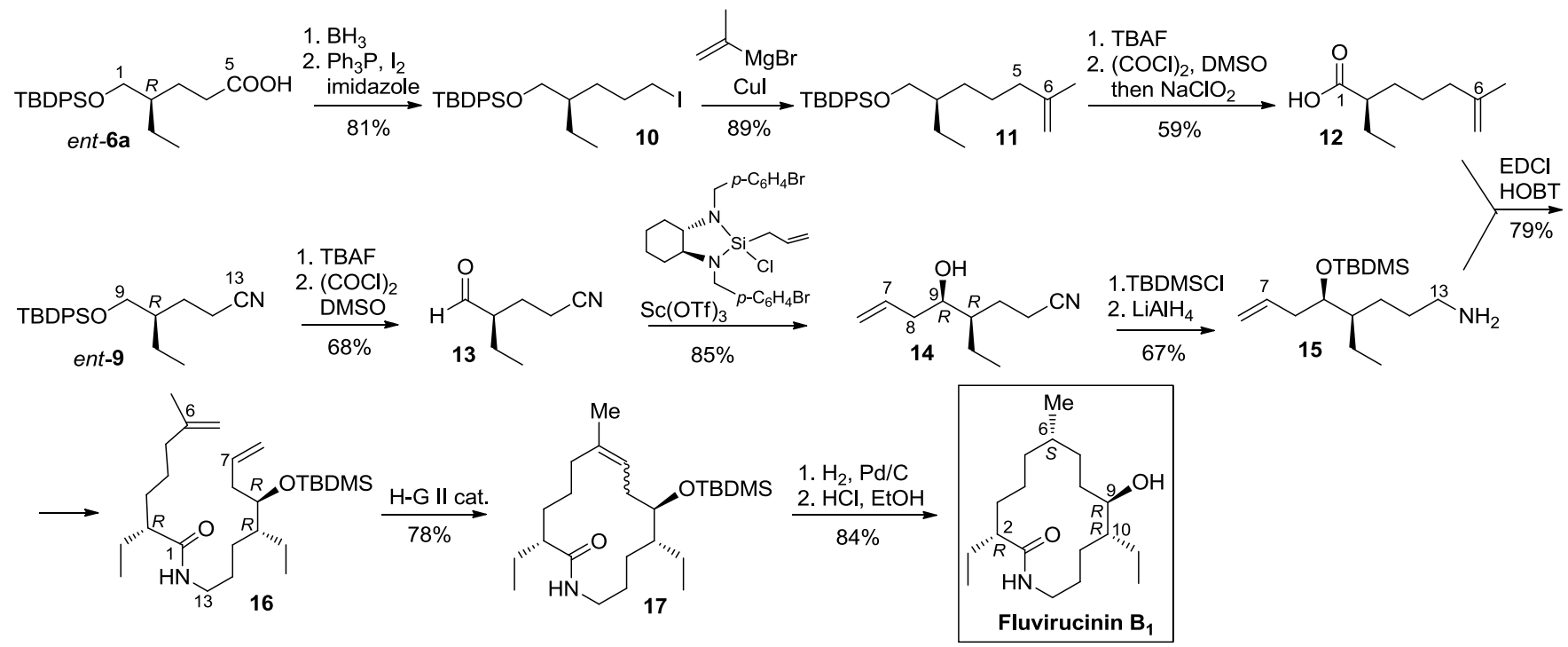

${ }^{a}$ The carbon numbering of the intermediates corresponds to that of fluvirucinin $\mathrm{B}_{1}$

A subsequent cross-coupling with 2-propenylmagnesium bromide in the presence of a catalytic amount of $\mathrm{CuI}^{16}$ (bond formed $\mathrm{C}_{5}-\mathrm{C}_{6}$ ) provided the protected alcohol 11, which was desilylated and oxidized to carboxylic acid $\mathbf{1 2}$ (23\% overall yield from $\mathbf{1}$ ).

On the other hand, after the protected hydroxy nitrile ent-9 was converted to aldehyde 13, a stereoselective allylation using the $(S, S)$-Leighton reagent ${ }^{17}$ installed the $\mathrm{C}-9$ stereogenic center to give homoallylic syn alcohol $14^{18}$ (bond formed $\mathrm{C}_{8}-$ $\mathrm{C}_{9}$ ). Protection of the hydroxy group of $\mathbf{1 4}$, followed by reduction of the cyano group, afforded amine $\mathbf{1 5}$ (the $\mathrm{C}_{7}-\mathrm{N}$ fragment of fluvirucinins B) in $21 \%$ overall yield from 1.

Coupling of the two fragments, carboxylic acid $\mathbf{1 2}$ and amine 15, took place in excellent yield to give amide 16. A subsequent ring-closing metathesis reaction (bond formed $\mathrm{C}_{6}-$ $\mathrm{C}_{7}$ ), followed by stereoselective catalytic hydrogenation of the resulting 1.2:1 mixture of trisubstituted olefins 17, generated the C-6 stereocenter of the macrocycle, ${ }^{19}$ leading to the $O$-protected fluvirucinin derivative 18. The NMR data of our silyl derivative $\mathbf{1 8}$ matched those reported in the literature, ${ }^{5 b, 9 b}$

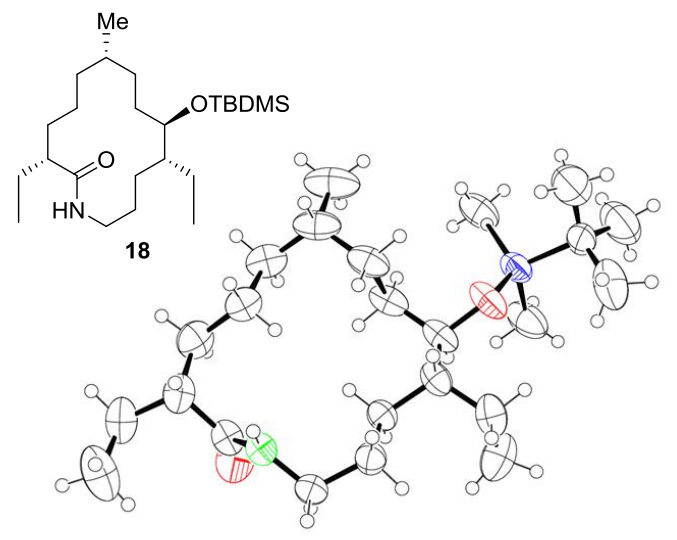

Figure 2. X-ray crystal structure of the fluvirucinin $\mathrm{B}_{1}$ precursor 18. and its $\mathrm{mp}$ and absolute rotation were consistent with those previously reported. ${ }^{9 b}$ Additionally, the absolute configuration of 18 was unambiguously established by X-ray crystallographyic analysis ${ }^{20}$ (Figure 2). A final removal of the silyl protecting group completed the synthesis of fluvirucinin $\mathrm{B}_{1}$, whose NMR data and $[\alpha]$ value are reported for the first time (see the Supporting Information).

The convergent enantioselective synthesis of fluvirucinin $\mathrm{B}_{1}$ herein reported consists of 12 linear synthetic steps from phenylglycinol-derived lactam $\mathbf{1}^{21}$ in the longest linear sequence. The overall yield was $11 \%$, which compares advantageously with previous syntheses ${ }^{9}$ of this aglycon. The synthesis also features an unprecedented oxidation of phenylglycinol-derived secondary amines $\mathbf{5}$ to diversely substituted enantiopure 5hydroxypentanoic acid derivatives $\mathbf{6}$. By using an appropriate alkenyl Grignard reagent in the assembly of the $\mathrm{C}_{1}-\mathrm{C}_{6}$ fragment, the strategy we have developed could be applied to the synthesis of fluvirucinins $\mathrm{B}_{0}$ and $\mathrm{B}_{2}-{ }_{5}$.

\section{ASSOCIATED CONTENT}

\section{Supporting Information}

The Supporting Information is available free of charge on the ACS Publications website.

Experimental procedures, product characterizations, and ${ }^{1} \mathrm{H}$ and ${ }^{13} \mathrm{C}$ NMR spectra (PDF)

Crystallographic data for compound $\mathbf{1 8}$ (CIF)

\section{AUTHOR INFORMATION}

\section{Corresponding Authors}

*E-mail: joanbosch@ub.edu

*E-mail: amat@ub.edu

Notes

The authors declare no competing financial interest. 


\section{ACKNOWLEDGMENTS}

Financial support from the Spanish Ministry of Economy and Competitiveness/FEDER (Projects CTQ2012-35250 and CTQ2015-65384-R) and the Generalitat de Catalunya (Grant No. 2014-SGR-155) is gratefully acknowledged. We also acknowledge the networking contribution from the COST Action CM1407.

\section{REFERENCES}

(1) (a) Hegde, V. R.; Patel, M. G.; Gullo, V. P.; Ganguly, A. K.; Sarre, O.; Puar, M. S.; McPhail, A. T. J. Am. Chem. Soc. 1990, 112 , 6403-6405. (b) Hegde, V. R.; Patel, M. G.; Gullo, V. P.; Puar, M. S. J. Chem. Soc., Chem. Commun. 1991, 810-812. (c) Hegde, V.; Patel, M.; Horan, A.; Gullo, V.; Marquez, J.; Gunnarsson, I.; Gentile, F.; Loebenberg, D.; King, A.; Puar, M.; Pramanik, B. J. Antibiot. 1992, 45, 624-632. (d) Cooper, R.; Truumees, I.; Yarborough, R.; Loebenberg, D.; Marquez, J.; Horan, A.; Patel, M.; Gullo, V.; Puar, M.; Pramanik, B. J. Antibiot. 1992, 45, 633-638.

(2) Naruse, N.; Tenmyo, O.; Kawano, K.; Tomita, K.; Ohgusa, N.; Miyaki, T.; Konishi, M.; Oki, T. J. Antibiot. 1991, 44, 733-740. (b) Naruse, N.; Tsuno, T.; Sawqada, Y.; Konishi, M.; Oki, T. J. Antibiot. 1991, 44, 741-755. (c) Naruse, N.; Konishi, M.; Oki, T.; Inouye, Y.; Kakisawa, H. J. Antibiot. 1991, 44, 756-761.

(3) (a) Ayers, S.; Zink, D. L.; Mohn, K.; Powell, J. S.; Brown, C. M.; Murphy, T.; Grund, A.; Genilloud, O.; Salazar, O.; Thompson, D.; Singh, S. B. J. Nat. Prod. 2007, 70, 1371-1373. (b) Ayers, S.; Zink, D. L.; Powell, J. S.; Brown, C. M.; Grund, A.; Genilloud, O.; Salazar, O.; Thompson, D.; Singh, S. B. J. Antibiot. 2008, 61, 59-62.

(4) (a) For the biosynthesis of the aglycons of fluvirucins $B_{1}, B_{2}$, and $\mathrm{B}_{3}$, see: Puar, M. S.; Gullo, V.; Gunnarsson, I.; Hegde, V.; Patel, M.; Schwartz, J. Bioorg. Med. Chem. Lett. 1992, 2, 575-578. (b) For the identification and characterization of the fluvirucin $B_{1}$ polyketide synthase, see: Lin, T.-Y.; Borketey, L. S.; Prasad, G.; Waters, S. A.; Schnarr, N. A. ACS Synth. Biol. 2013, 2, 635-642.

(5) Fluvirucin $\mathrm{B}_{1}$ : (a) Xu, Z.; Johannes, C. W.; Salman, S. S.; Hoveyda, A. H. J. Am. Chem. Soc. 1996, 118, 10926-10927. (b) Xu, Z.; Johannes, C. W.; Houri, A. F.; La, D. S.; Cogan, D. A.; Hofilena, G. E.; Hoveyda, A. H. J. Am. Chem. Soc. 1997, 119, 10302-10316.

(6) Fluvirucinin $A_{1}$ : (a) Suh, Y.-G.; Kim, S.-A.; Jung, J.-K.; Shin, D.-Y.; Min, K.-H.; Koo, B.-A.; Kim, H.-S. Angew. Chem. Int. Ed. 1999, 38, 3545-3547. (b) Liang, B.; Negishi, E. Org. Lett. 2008, 10, 193-195. (c) Son, S.; Fu, G. C. J. Am. Chem. Soc. 2008, 130, 27562757 (formal). (d) Radha Krishna, P. ; Anitha, K. Tetrahedron Lett. 2011, 52, 4546-4549. (e) Suh, Y.-G.; Lee, Y.-S.; Kim, S.-H.; Jung, J.K.; Yun, H.; Jang, J.; Kim, N.-J.; Jung, J.-W. Org. Biomol. Chem. 2012, 10, 561-568.

(7) Fluvirucinin $\mathrm{A}_{2}$ : Lee, Y.-S.; Jung, J.-W.; Kim, S.-H.; Jung, J.K.; Paek, S.-M.; Kim, N.-J.; Chang, D.-J.; Lee, J.; Suh, Y. G. Org. Lett. 2010, 12, 2040-2043.

(8) Fluvirucinin $\mathrm{B}_{0}$ : Baltrusch, A. W.; Bracher, F. Synlett 2002, 1724-1726.

(9) Fluvirucinin $B_{1}$ : (a) Houri, A. F.; Xu, Z.; Cogan, D. A.; Hoveyda, A. H. J. Am. Chem. Soc. 1995, 117, 2943-2944. (b) Trost, B. M.; Ceschi, M. A.; König, B. Angew. Chem. Int. Ed. 1997, 36, 14861489. (c) Martín, M.; Mas, G.; Urpí, F.; Vilarrasa, J. Angew. Chem. Int. Ed. 1999, 38, 3086-3089. See also ref 5b.
(10) Fluvirucinin $B_{2-5}$ : Llàcer, E.; Urpí, F.; Vilarrasa, J. Org. Lett. 2009, 11, 3198-3201.

(11) Guignard, G.; Llor, N.; Urbina, A.; Bosch, J.; Amat, M. Eur. J. Org. Chem. 2016, 693-703.

(12) Gilbert, K. E.; Borden, W. T. J. Org. Chem. 1979, 44, 659661.

(13) For the preparation of nitrones by oxidation of secondary amines, see: (a) Murahashi, S.-I.; Mitsui, H.; Shiota, T.; Tsuda, T.; Watanabe, S. J. Org. Chem. 1990, 55, 1736-1744. (b) Marcantoni, E.; Petrini, M.; Polimanti, O. Tetrahedron Lett. 1995, 36, 3561-3562. (c) Colonna, S.; Pironti, V.; Carrea, G.; Pasta, P.; Zambianchi, F. Tetrahedron 2004, 60, 569-575. (d) Gella, C.; Ferrer, E.; Alibés, R.; Busqué, F.; de March, P.; Figueredo, M.; Font, J. J. Org. Chem. 2009, 74, 6365-6367.

(14) For peracid-promoted oxidative ring-opening of cyclic nitrones, see: Bapat, J. B.; Durie, A. Aust. J. Chem. 1984, 37, 211219.

(15) (a) Iida, S.; Togo, J. Tetrahedron 2007, 63, 8274-8281. See also: (b) Veisi, H. Synthesis 2010, 2631-2635. (c) Zhu, C.; Sun, C.; Wei, Y. Synthesis 2010, 4235-4241.

(16) For copper-catalyzed couplings of alkenyl Grignard reagents with primary alkyl iodides, see: (a) Derguini-Boumechal, F.; Linstrumelle, G. Tetrahedron Lett. 1976, 3225-3226. For more recent examples, see: (b) Takahashi, M.; Dodo, K.; Hashimoto, Y.; Shirai, R. Tetrahedron Lett. 2000, 41, 2111-2114. (c) Kochi, T.; Ellman, J. A. J. Am. Chem. Soc. 2004, 126, 15652-15653. (d) Terayama, N.; Yasui, E.; Mizukami, M.; Miyashita, M.; Nagumo, S. Org. Lett. 2014, 16, 2794-2797. For the use of iron catalysts, see: (e) Guérinot, A.; Reymond, S.; Cossy, J. Angew. Chem. Int. Ed. 2007, 46, 6521-6524. (f) Cahiez, G.; Duplais, C.; Moyeux, A. Org. Lett. 2007, 9, 3253-3254.

(17) (a) Kubota, K.; Leighton, J. L. Angew. Chem. Int. Ed. 2003, 946-948. For synthetic applications, see: (b) Vintonyak, V. V.; Maier, M. E. Org. Lett. 2008, 10, 1239-1242. (c) Harsh, P.; O’Doherty, G. A. Tetrahedron 2009, 65, 5051-5055, and references cited therein. (d) For the use of $\mathrm{Sc}(\mathrm{OTf})_{3}$ as a catalyst in enantioselective Leighton allylations, see: Kim, H.; Ho, S.; Leighton, J. L. J. Am. Chem. Soc. 2011, 133, 6517-6520. See also ref 10.

(18) Minor amounts $(\mathrm{dr}=9: 1)$ of the anti adduct were detected by NMR. Purification of amine $\mathbf{1 5}$ afforded a single diastereoisomer.

(19) A similar remote macrocyclic stereocontrol in the synthesis of fluvirucinins was first observed by Hoveyda ${ }^{5}$ in the hydrogenation of related macrocyclic olefins bearing a trisubstituted $\mathrm{C}_{5}-\mathrm{C}_{6}$ (instead of $\mathrm{C}_{6}-\mathrm{C}_{7}$ ) double bond.

(20) CCDC 1440667 contains the supplementary crystallographic data for compound 18. This data can be obtained free of charge from the Cambridge Crystallographic Data Centre via www.ccdc.cam.ac.uk/data request/cif.

(21) For recent enantioselective total syntheses of complex alkaloids using aminoalcohol-derived lactams as starting materials, see: (a) Amat, M.; Ramos, C.; Pérez, M.; Molins, E.; Florindo, P.; Santos, M. M. M.; Bosch, J. Chem. Commun. 2013, 49, 1954-1956. (b) Ballette, R.; Pérez, M.; Proto, S.; Amat, M.; Bosch, J. Angew. Chem. Int. Ed. 2014, 53, 6202-6205. (c) Amat, M.; Guignard, G.; Llor, N.; Bosch, J. J. Org. Chem. 2014, 79, 2792-2802. (d) Amat, M.; Pinto, A.; Griera, R.; Bosch, J. Chem. Eur. J. 2015, 21, 12804-12808. For reviews, see: (e) Amat, M.; Pérez, M.; Bosch, J. Synlett 2011, 143160. (f) Amat, M.; Llor, N.; Griera, R.; Pérez, M.; Bosch, J. Nat. Prod. Commun. 2011, 6, 515-526. 